\title{
Leab, Woods, and Deforestation as an Influence on Place-Names
}

\section{GEORGE R.STEWART}

\begin{abstract}
A
NGLO-SAXon leah appears in many place-names, e.g., Lea, Leigh, Berkeley, Thornleigh, Healaugh, Barlow, Barclay. A. H. Smith in English Place-Name Elements (1956) has treated this element fully (2. 18-22), giving its meanings as 'a wood, a clearing in a wood,' and indicating that 'clearing' is to be taken as including a 'natural open space in a wood, a glade.'

We are thus faced with the anomaly that leah sometimes meant an area distinguishable by being overgrown by trees, and sometimes an area distinguishable by not being overgrown. Smith presents no evidence, and offers no suggestion, as to how the anomaly can have arisen. I here make such an attempt. ${ }^{1}$

Since leah is (again to quote Smith) "infrequent in literary use," the exact determination of its meanings is difficult. In particular, the question may be raised as to which of the two was the original one - or, at least, the earlier one. ${ }^{2}$

The evidence appears to me to point to 'treeless area' (whether natural or man-made) as the earlier meaning:

(1) The only gloss cited by Smith as being pertinent renders leah by campus. Such a translation would indicate that a leah was ordinarily considered to be treeless.

(2) Close phonetic and semantic correspondences seem to connect leah with leoht, meaning 'light.' If this relationship is accepted, the

1 One can, of course, assume that the two meanings go back to two different words, which came to be phonetically indistinguishable. Such a conclusion, without evidence, should be accepted only as a last resort. No one seems to have suggested it in this instance.

2 Smith makes no precise statement, but seems to favor 'wood' as the earlier meaning. OED gives only "a tract of open ground." E. Ekwall (Concise Oxford Dict. of Eng. Place-Names, ${ }^{3}$ [1947], p. 278) states: "The original meaning was 'an open place in a wood, a part in a wood with the trees scattered so that grass can grow."
\end{abstract}


earlier meaning must have been essentially 'a place of light,' i.e., 'a treeless, unshaded place in the forest.'

(3) The evidence of cognate languages favors 'open space.' In the Germanic languages the testimony is conflicting, e.g., ON $l o$, 'glade;' OHG, loh, 'grove;' MHG, loh, 'low brushwood, a clearing overgrown with brushwood.' (See Smith, op.cit., 2. 19.). The Latin lucus means 'grove,' but is considered to be connected with lux (luc-), and therefore once to have meant a treeless area. The Baltic languages (e.g., Lithuanian laukas) use words of this derivation to mean 'open space.' Sanskrit loka- had as its early meaning 'open space.' 3 The evidence of such an Indo-European language as Sanskrit, not closely connected with Germanic, is striking. The conclusion from the cognate words is thus that a word such as leah, from the word for light, and meaning a treeless area, either arose in early Indo-European times or else developed later in the various languages from the need for such a term in thick-forested country. ${ }^{4}$

(4) The evidence of Modern English lea, meaning 'meadow,' or 'open land,' according to Smith, cannot be conclusive, since it is late, chiefly poetic, and possibly confused with Anglo-Saxon laes, 'meadow.' Still, lea cannot be wholly disregarded. OED shows it occurring as early as the fourteenth century. It would seem likely to preserve the common meaning of the word in Middle English, and thus to confirm the evidence of the gloss campus for leah in Anglo-Saxon.

(5) The association of leah with "districts that were once heavily forested" (Smith, op.cit., 2. 18) might seem to argue for 'wood' as the common meaning, but actually argues strongly to the contrary, as the present study should demonstrate.

(6) The use of certain specifics with leah shows only that the element sometimes is to be taken as meaning 'wood,' but neither that it was commoner nor that it was the earlier usage. Here we have tree names, e.g., Oakleigh, Ashley, Elmley. Also, elements meaning 'staves,' e.g., Staveley, suggest a tree-grown rather than

${ }^{3}$ See C. D. Buck, A Dictionary of Selected Synonyms in the Principal IndoEuropean Languages (1949), p. 27, for the words in Latin, Sanskrit, and the Baltic languages.

4 The existence of a general Indo-European word meaning 'open space, glade, clearing' and connected with 'light' should indicate a forest-dwelling people, and so may be possible evidence on that vexed problem, the place of Indo-European origin. 
a treeless place. Such names may, however, indicate open spaces. An opening might be called Oakleigh because an oak-tree stood isolated in it or prominent along its edge. Staveley might denote a meadow where staves were piled after having been cut in the neighboring wood. Still there is no need to try to explain away such words, and the citations offered by Smith (2.19) conclusively demonstrate that leah sometimes meant 'wood,' even in Anglo-Saxon times. ${ }^{5}$ At the same time the rarity of such forms as Graseley (grassleah) may be taken to show that being grass-grown was a regular and not a differentiating feature of a leah. The common Bentley indicates an open space with a special kind of grass, and a specific from a cultivated plant, e.g., Wheatley, Beanley, definitely indicates a field, doubtless earlier an uncultivated glade or clearing.

The present argument thus begins with the belief that leah first meant a treeless area, and probably had no other meaning at the time of the coming of the Germanic tribes to Britain.

There would seem to be no need (and there would be little evidence) to carry the argument back to conditions as they may have existed on the continent. In their new home, however, the Angles and Saxons found large areas that were forested. ${ }^{6} \mathrm{~A}$ broad-leaf, temperate-zone forest, however, is never without openings. These may occur where the soil is too wet or too rocky to support treegrowth, or where windfalls or lightning-set fires have produced temporary gaps. They may also be the result of purposeful clearing by men. There is no need for the present study to distinguish between the two types of spaces. At least we can be sure that openings existed. The boundaries of some of them would have been ragged, and the areas of others would have been partially overgrown with bushes and saplings. Still, many of them would have been easily distinguishable from the surrounding forest, and would thus have

5 The most striking use of leah as 'wood' is its application to a large forest in Andredesleage. But see ibid., under the discussion of wald.

6 Even if we should assume a considerable clearing of forest in Roman times, the disturbed conditions of the period of conquest would have tended to restore the original conditions. Though deforestation is laborious and so is bound to be slow, afforestation can be rapid in a good tree-growing country such as much of England. Rapidly-growing and quick-spreading trees, such as elms, can blot out fields in ten or twenty years. The process would be the more rapid if - as would have been likely under the conditions - the land was often deserted for considerable periods, so that tree-growth was not hindered by domestic grazing animals. 
possessed entity, one condition which must be a property of anything to which a name is to be given.

Moreover, these openings were of great importance to any people who lived in the region. As Caesar and other classical writers have made us aware, the forests of northern Europe were dank and dismal. A 'place of light' was certainly prized, because there one could enjoy the cheerfulness and warmth of the sun. There a band of invading Angles or Saxons could establish their village. There they could cultivate their crops successfully. There the horses, cattle, and sheep could graze.

Some years ago I laid down what I may call the Principle of Entity and Use, i.e., that a place will be named when it can be distinguished as a thing in itself (possesses entity), and when it is of enough importance in the lives of the people of the region to make its distinction from similar places useful. ${ }^{7}$ The openings in the forest must have fulfilled both requirements, and therefore most of them, if the Celtic names were not retained, would soon have been named by the invaders.

Doubtless each of them was at once called a leah, and distinguishing specifics were soon added. The situation may be represented diagrammatically (see Diagram A).

Shown here is a forested area (black) with five openings (white) of different sizes and shapes. No exact scale need be assigned to the diagram, since a leah may be conceived as of almost any size. In actuality, as anyone familiar with a forested country will readily agree, the openings themselves would stand out as clearly as the spots do on the diagram.

The Angles and Saxons, having established themselves, apparently increased in population in the course of time. Along with this growth would have occurred a progressive clearing of the forest to provide more land for cultivation and grazing. At the same time, therefore, we may consider that the area shown in Diagram A came to look like what is shown in Diagram B. Here the clearing has progressed until some openings shown in Diagram A have coalesced. Also a new clearing has appeared, and some bits of woodland remain inside the larger open spaces. Undoubtedly there would

\footnotetext{
7 See "What is Named ? - Towns, Islands, Mountains, Rivers, Capes" in Essays and Studies by Members of the Dept. of English, Univ. of Calif., 1943.
} 
have to be some shifts of place-names to meet this new situation, but there is no need to speculate as to what they may have been, since Diagram B represents merely a transitional stage.

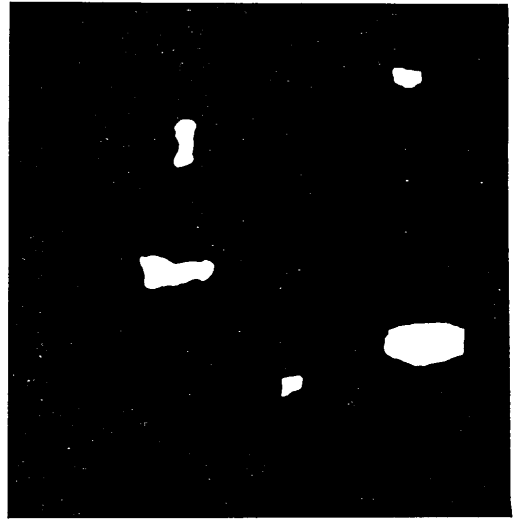

Diagram A

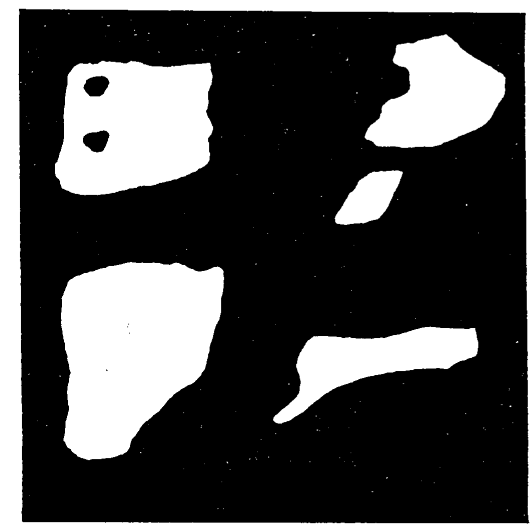

Diagram B

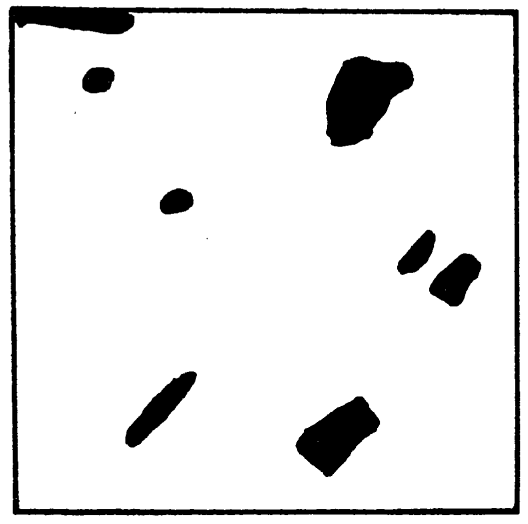

Diagram $\mathbf{C}$

Population, we may believe, continued to increase, with still further inroads upon the forest. After several centuries of occupation we may consider that the situation of Diagram A has been reversed, as shown in Diagram C.

By this time the open spaces have coalesced, and therefore have disappeared as entities. By the same process each of the remaining bits of woodland has attained an entity that would be equally as strong in actuality as it is in the diagram. 
At the same time these wooded areas would retain some importance in the lives of the inhabitants - as sources of wood and nuts, as feeding-grounds for swine, as places of refuge. Possessing both entity and use, therefore, they would require names, just as the open areas had previously done.

The ordinary word for a forested area was wudu, i.e., the ancestor of the modern wood. Undoubtedly, many such areas as are represented in Diagram $\mathrm{C}$ were merely called by that common term, and then by addition of some specific were furnished with real placenames.

But what happened to the various place-names ending in -leah? Many of them, we may suppose, simply vanished, i.e., the people themselves ceased to use the names which no longer denoted anything that could be marked off as an entity.

The Principle of Entity and Use, however, applies chiefly to the giving of names. Once a name has been established, it may continue even after the entity is lost. For instance, the Isle of Ely was given that name because it was surrounded by lagoons and marshes. Although it has ceased to be so surrounded, the name survives.

Similarly, as the map of England testifies abundantly, many places in -leah survived the disappearance of the leah. Some of them had become the names of villages or farms, and as a result many habitation-names now end in -ley, etc. Attached to a village, the name continued to denote an entity. Its failure to describe would be of no importance, since no one seems to mind if a habitationname fails to describe. Charlton remains after the village is no longer a place for churls to live, and Chelmsford survives the replacement of its ford without becoming Chelmsbridge.

At the same time we should remember that the creation of a new place-name involves a certain amount of what we might call work, and that mankind is generally loath to do more work than is necessary. The naming of the American West, for instance, can supply us with examples of this parsimony. A name that was displaced might not be discarded, as we would expect, but would be frugally placed upon a near-by feature. ${ }^{8}$

${ }^{8}$ I illustrated this point with reference to Cassia Creek in a paper read at the Seventh International Congress of Onomastic Sciences (1961) - soon, I presume, to be published in the Proceedings. 
Against this background we may try to explain the development of the meaning 'wood' for leah. Beyond the reach of memory, we may suppose, some villagers had known a certain open space as Stanley because of its stoniness. Eventually the open space vanished into general openness. You could no longer walk through the forest and then know yourself to be at Stanley when you came out into the open. Yet there was still need to go to that vicinity. All that remained for a landmark was a bit of near-by woodland. The name Stanley could then continue in use. In the minds of the older people, for a while, it might still be taken to mean, not actually the wood, but the part of the general open space which had always been known to them as Stanley and which now lay close to one of the remaining wooded areas. But such a theoretical distinction could not be long maintained. In the next generation the people who continued to go to Stanley would necessarily have to think of it as being the only landmark by which they could tell that they had arrived where they had set out to go. They would, therefore, consider Stanley to be, not the open space, but the wood.

At this point, then, we may consider the process to be complete. In regions that were still forested, leah continued to denote an open space. In cleared regions this element was treated in three different ways: (1) it disappeared, (2) it survived as a conventional and no longer descriptive habitation-name, (3) it was transferred to one of the remaining isolated areas of forest, and thus in time came to have the meaning 'wood.'

The question may be raised as to whether the process could work in the opposite direction, i.e., whether an original word meaning 'wood' might come to mean 'open space' in a time of advancing forest, such as we would have if we took the time-sequence of the diagrams to be C-B-A.

Though the speculation is attractive, I can scarcely imagine conditions which would make such a shift of meaning possible. If the forest advanced because the area was depopulated, the names would vanish along with the people. If we assume a gradual decline of population, this would naturally be associated with a concentration of people in favored areas and loss of place-names in the areas where the forest was advancing. We should have to suppose a condition of advancing forest and of a population remaining static and maintaining its distribution. Such a supposition runs counter 
to reality, since the "carrying power" of forested country, where the sun's energy is chiefly expended in producing inedible leaves and wood, cannot be imagined as equaling that of open country, where the sun's energy chiefly produces edible crops and grass for feeding animals. ${ }^{9}$

The development of words cognate to leah in some other languages has already been cited. Of these the most interesting is the Latin lucus, which has given rise to the phrase "lucus a non lucendo." Presumably its development was similar to that of leah, but it went the whole way. ${ }^{10}$

Anglo-Saxon wald offers an analogy with leah for which we may again quote Smith (op.cit., 2. 240):

With the clearing of the large forest-tracts... the term wald came to lose its association with woodland and now described the newly developing type of landscape; in ME there are few allusions to wald meaning 'woodland,' but there is an increasing number of contexts which suggest the sense 'hill, down' ... and 'a piece of open country, an elevated stretch of open country or moorland.'

One should remember that wald may be connected with wild, and in any case sounds so much like it as to suggest a relationship. (I remember encountering "the Weald" in Kipling's Puck of Pook's Hill, when I read it as a child, and vaguely associating the unfamiliar term with "the wild," since my virginal American ears bad never encountered this Briticism.) If the word thus always had a suggestion of 'wild country,' it could readily shift in meaning from 'forest' to 'uninhabited, wild country' of any kind.

Something of this sort seems to have happened with the cognate word in Icelandic, where it could never have been applied to a

9 Nevertheless, mark now means 'field' in the Scandinavian languages, but once meant 'forest.' The still earlier meaning, however, was 'boundary,' as with AS mearc. The transition boundary-borderland-forest seems easy. But the transition forestfield, as stated above, seems difficult. Could 'field' have developed immediately from 'boundary,' since a field is something usually marked off by a definite boundary ?

10 See Buck, op.cit., p. 47. - The cognate of the AS holt, 'wood, thicket' was applied in Iceland to a bare hill or ridge. This example raises the question of what happens when a forest-dwelling people migrate to an unforested country, but this inquiry lies beyond the limits of the present study. I am grateful to my colleage Madison S. Beeler for these examples from Icelandic, and for other suggestions and criticisms. 
forest, since there were none. The immigrants to Iceland brought vollr with them, and it is applied in the meaning 'untilled field.'10

The English settlement in the wooded region which is now the eastern United States might be expected to yield some analogies. Unfortunately the place-names of that region have not yet been studied in much detail, so that no conclusion can be offered at present.

Farther west, where treeless areas were commoner and larger, the situation is a little clearer. Meadow was used, and prairie was adopted from the French. Grove was used for a small area of trees. Both grove and prairie survive in town names. Many of these are no longer descriptive, since the original grove may have been cut down and since settlement has resulted in many trees being planted in the originally treeless prairies. ${ }^{11}$

An interesting development is that of woods. Although the English settlers were familiar with wood for a forested area, they could not make use of it in America. Wood, by the seventeenth century, had come to mean something isolated and rather small, since no large forests were left in England. It meant also something with definite entity (as in Diagram $\mathrm{C}$ ), which could have a specific name applied to it. But the seemingly endless forest of America was different, and could not be broken down into separate entities to be given names.

Accordingly the whole forested area came to be known simply as the woods. The usage may be traced from the very beginning. For example, John Smith in his True Relation (1608) wrote, "divers out of the woods would meet with us."

The exact suggestion of the plural is difficult to ascertain. It may here be a kind of collective, on the analogy of the Highlands, the Midlands, the Great Plains. Possibly the settler thought of the woods as an agglomeration of an indefinite number of small forested areas, each of which might have been considered to be a wood, just as the mountains may be thought the summation of many individual peaks and ridges.

Woods worked deeply into the American consciousness, and is still current. It has given rise to such expressions as the backwoods, backwoodsman, take to the woods, neck of the woods, woods road.

11 See also my Names on the Land (1945 or 1958), p. 153. 
Woods was also, by the nineteenth century, accepted by American poets. In Bryant's famous lines in Thanatopsis (1811),

Or lose thyself in the continuous woods

Where rolls the Oregon

the adjective continuous establishes the American meaning of woods. Lanier's most famous poem, A Ballad of Trees and the Master, may even be said to be built around this usage of the word, as in the line,

\section{Into the woods my Master went.}

With the felling of the forest a situation resulted which was similar to that in England a thousand years earlier. The treeless area had now expanded and amalgamated, but many individual wooded areas remained. Some of these, especially in the mountainous regions, were still large enough to deserve the term the woods. But in more thickly settled regions many areas of isolated woodland were no more than a few acres in extent. Each of these was now called $a$ woods, since the singular had in the course of a few centuries gone out of use as a topographical term and in popular usage denoted only the material. At some time, moreover, woods became a grammatical singular, though remaining also a plural and quasi-collective. Naturally, also, woods was often associated with a specific and thus became a fully developed place-name, as with Spangler's Woods, on the battlefield of Gettysburg. One would suspect that woods as a singular developed ás soon as the forest was cut back. The earliest citation of it that I have located is for 1814, "Captain Smith with his 20 men occupied a thick woods." 12 .

The examples here cited seem to me sufficient to demonstrate that deforestation is likely to have a definite influence upon placenames.

Berkeley, California

12 See G. D. McJimsey, Topographic Terms in Virginia (1940), p. 140. 